\title{
Hypertrichosis with hereditary gingival hyperplasia
}

\author{
G. B. WINTER and M. J. SIMPKISS \\ From the Institute of Dental Surgery, Eastman Dental Hospital, London; and Poole General Hospital, Poole, \\ Dorset
}

\begin{abstract}
Winter, G. B., and Simpkiss, M. J. (1974). Archives of Disease in Childhood, 49, 394. Hypertrichosis with hereditary gingival hyperplasia. Two cases of infantile hypertrichosis who subsequently developed oral abnormalities are described. In one case generalized gingival hyperplasia was associated with retarded eruption of deciduous and permanent teeth and macrodontia. In the second case the mucosal hyperplasia was limited to the palatal surface.
\end{abstract}

Although reports of hypertrichosis associated with gingival hyperplasia are rare in published reports, the condition was initially described over a century ago by Gross in 1856 (Gorlin and Pindborg, 1964). These forms of excessive hairiness have varied considerably in age of onset and degree; in several cases the condition has been noted at birth or shortly after. Hypertrichosis of this rare type, presenting in infancy, may be confused with other conditions and lead to needless investigation. For this reason 2 further cases of infantile hypertrichosis who developed oral abnormalities later in childhood are described.

\section{Case reports}

Case 1. The first patient, a Caucasian girl of 14 years, was born at term to unrelated parents after an uneventful pregnancy. Soon after birth she was noted to have an excessive growth of hair on the face, upper limbs, and down the middle of the back. The gum pads were exceedingly thick by 4 months of age and teething did not begin until 15 months. The eruption of the second deciduous molars was delayed until the 6 th year. In all other respects she had been a normal healthy child. No family history of congenital abnormality was obtained, with the sole possibility that many of the paternal family had been of short stature.

She was first seen by us aged $7 \frac{1}{2}$ years with delayed eruption of her permanent teeth, none of which had emerged at this time. Clinical examination showed a mentally alert, well-built child with hypertrichosis, a prominent feature of which was extremely bushy eyebrows meeting in the midline over a wide and retruded nasal bridge. A downy growth of hair was present on the cheeks, chin, and upper lip, and a profuse growth of dark brown hair was present on both the upper and lower limbs and the middle of the back. The hairs on the forearms were $1-2 \mathrm{~cm}$ in length (Fig. 1). Generalized gingival hyperplasia was present, the tissue

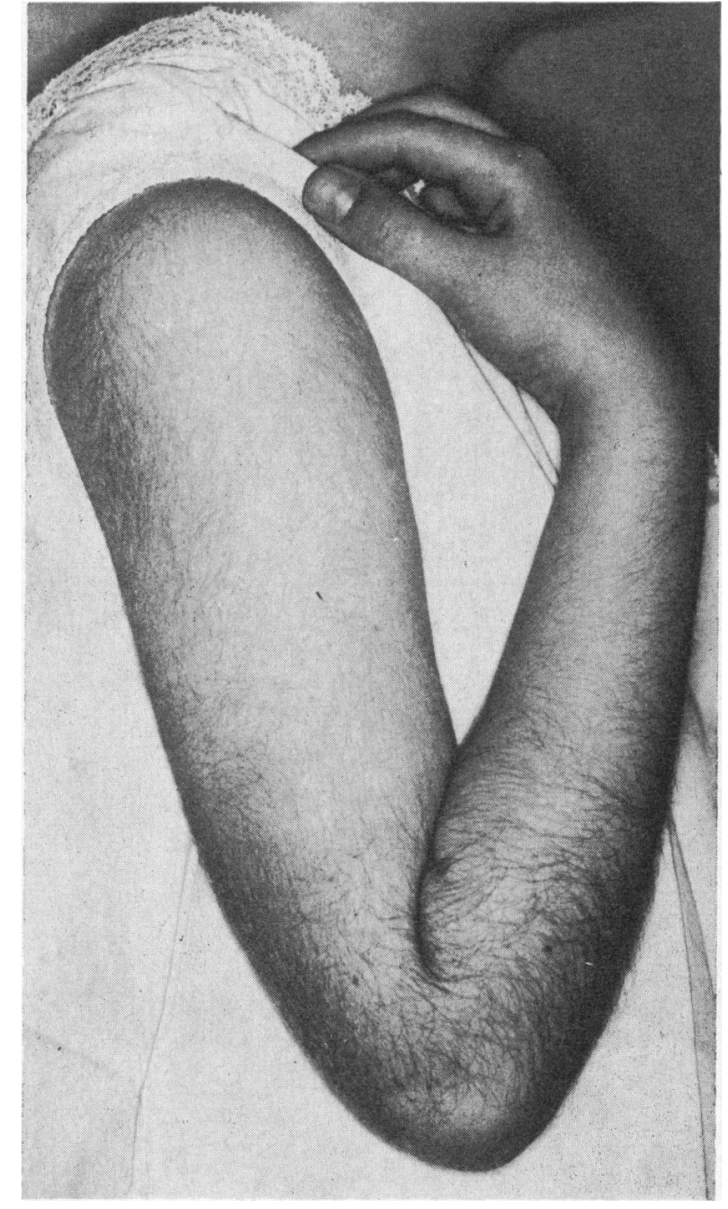

FIG. 1.-Case 1. Showing marked hypertrichosis of upper limbs. 


\section{Hypertrichosis with hereditary gingival hyperplasia}

being pale pink in colour, exceedingly thick, conspicuously stippled, and covered at least a half of the anatomical crowns of the deciduous teeth (Fig. 2). $X$-rays showed the presence of a normal complement of unerupted permanent teeth with the exception of congenitally absent 5. Her chromosomes were those of a normal female (Dr. C. O. Carter).

She was seen again at age 13 with a persistent delay in the eruption of her permanent teeth. Menarche had begun 6 months earlier. The frequent use of a depilatory cream had been effective in removing excessive hair from her limbs, while that on her face and back had apparently diminished spontaneously as she approached puberty.

Gross enlargement of gingival tissues was present and had increased considerably since the earlier dental examination. The gingival tissue was exceedingly thick, conspicuously stippled, and devoid of signs of inflammation. The only permanent teeth which had erupted into the mouth were $6 \quad 1 \mid \begin{array}{llll}12 & 6 .\end{array}$ The extremely

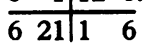

thick gingival tissue had prevented the erupted teeth from attaining their normal positions in the arch (Fig. 3). The crown of 27 was rotated through $90^{\circ}$ and was noted to be macrodont with a mesiodistal diameter of $8.0 \mathrm{~mm}$ (normal range 4.7-6.8 mm, Moorees et al., 1957). $L 2$ was displaced labially with a thick wedge of gingival tissue interposed between $\mid 12$ above a retained $b$. Other retained primary teeth included edcb/cde . Apart from

$$
\text { edc } / \text { bcde }
$$

the disturbance of occlusion created by the gingival hyperplasia, a conspicuous crowding of teeth was present in both jaws.

In the upper jaw the palatal anatomy was distorted both by gross thickening of the palatal mucosa covering the hard palate, especially that close to the gingival margins in the molar regions, and by the presence of bilateral bony tori midway between the central sulcus and the gingival margins. The central palatal vault appeared to be excessively high and to be indented by the nasal septum (Fig. 4).

After gingival surgery, restricted to the labial segments of each jaw, the incisor teeth erupted into reasonably normal positions within a period of 4 months (Fig. 5).

Further clinical and $x$-ray examination showed other macrodont teeth to be present; $\sqrt{2}$ was affected, with a mesiodistal crown diameter of $7.0 \mathrm{~mm}$, and the unerupted $\overline{5} 5$ appeared to have mesiodistal diameters of approximately $1.0 \mathrm{~cm}$ (normal range $6 \cdot 2-7 \cdot 9 \mathrm{~mm}$, Moorees et al., 1957). No significant abnormality could be detected elsewhere on $x$-ray examination, which included the metacarpals and phalanges of both hands and the cervical spine.

The very considerable aesthetic improvement brought about by the gingival surgery was mirrored by a considerable psychological improvement in the patient who was reported to be much more cheerful and willing to mix socially.

Case 2. The second patient, a Caucasian girl now aged 8 , had unrelated parents from whom no family history of gingival hyperplasia or hypertrichosis could be obtained. Birthweight $2.9 \mathrm{~kg}$.

Generalized hypertrichosis and prominent eyebrows were first noticed at 6 months of age and have persisted ever since (Fig. 6). At 13 months a normal excretion of 17-ketosteroids and 17-hydroxycorticosteroids in the urine was found, together with a normal 11-oxygenation index; intravenous pyelography was normal.

Hyperplasia of the palatal rugae was observed at age 51 years and has since increased (Fig. 7); the dentition in all other respects appears normal. More recently $x$-rays of chest, cervical spine, hands, and skull showed no abnormality, and the bone age is within the normal range.

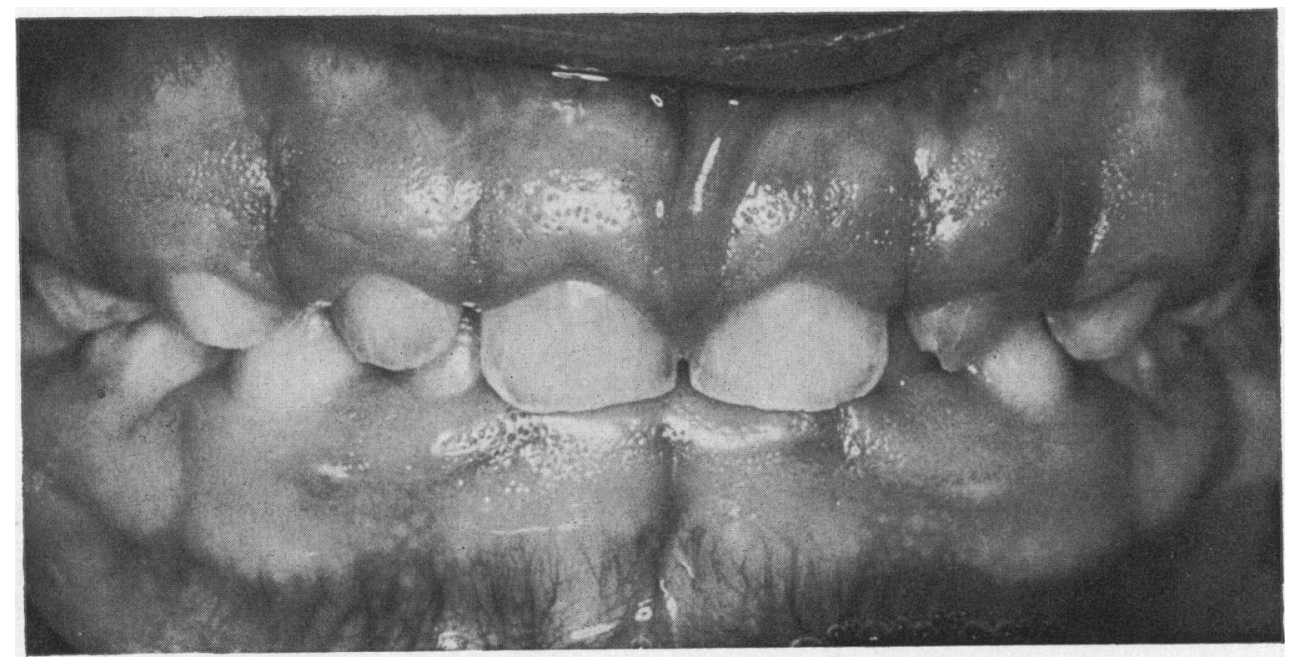

Fig. 2.-Case 1. Gingival hyperplasia showing evidence of marked stippling. 


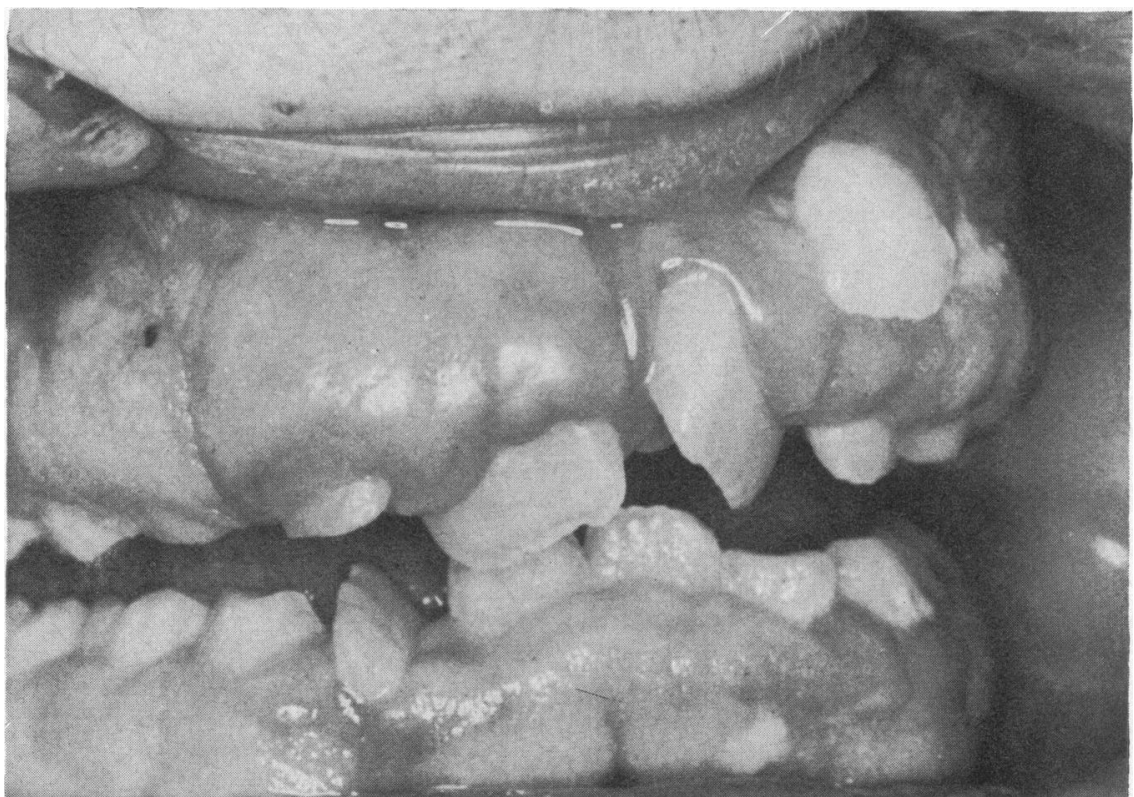

FIG. 3.-Case 1. Gross gingival hyperplasia preventing normal eruption of permanent incisors.

Her height has been at a normal growth rate along the 3 rd centile and weight on the 50th centile. Her mother and father were noted to be 155 and $173 \mathrm{~cm}$ tall, respectively. Her intelligence is normal.

\section{Discussion}

While the association of gingival hyperplasia and hypertrichosis has been reported on just over 50 occasions (Witkop, 1971), many more cases have been described with gingival changes alone, and Rushton (1957) considered them to form part of the same clinical syndrome. The condition has been reported under a variety of synonyms which include hereditary gingival fibromatosis, elephantiasis

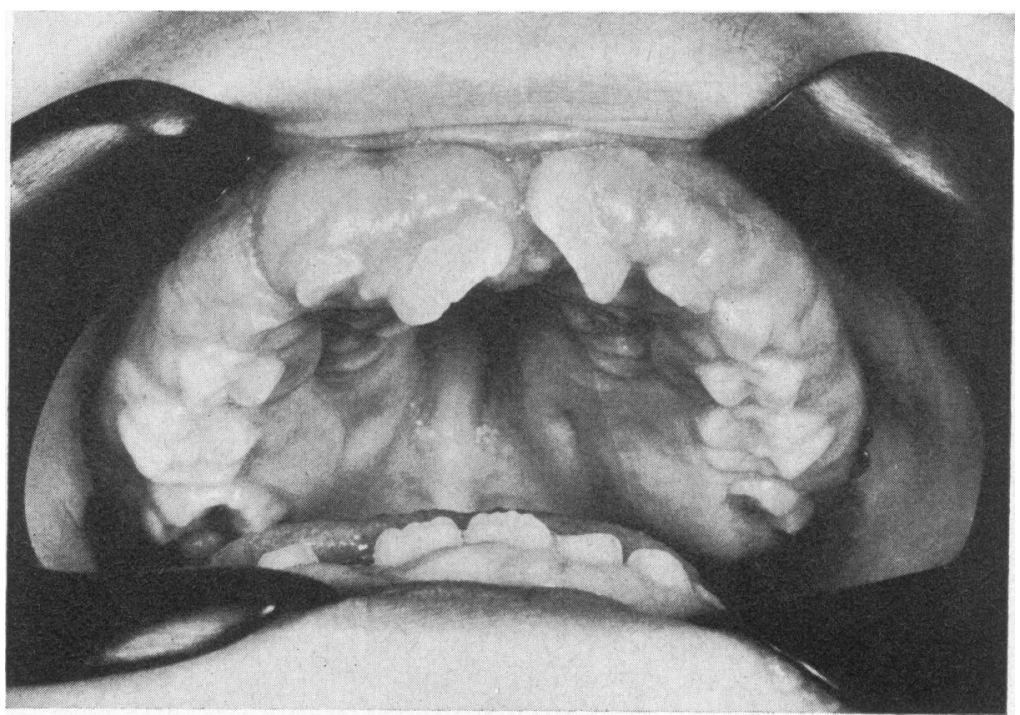

Fig. 4.-Case 1. Bilateral bony tori and impression of nasal septum on palatal vault. 


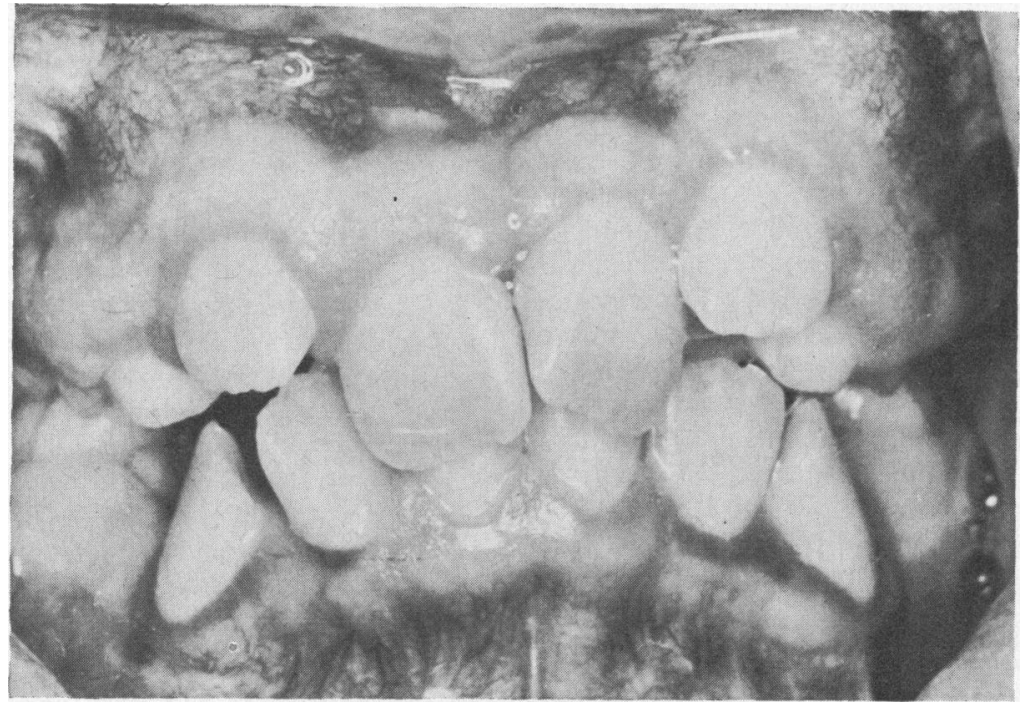

Fig. 5.-Case 1. Appearance of incisor teeth after operation.

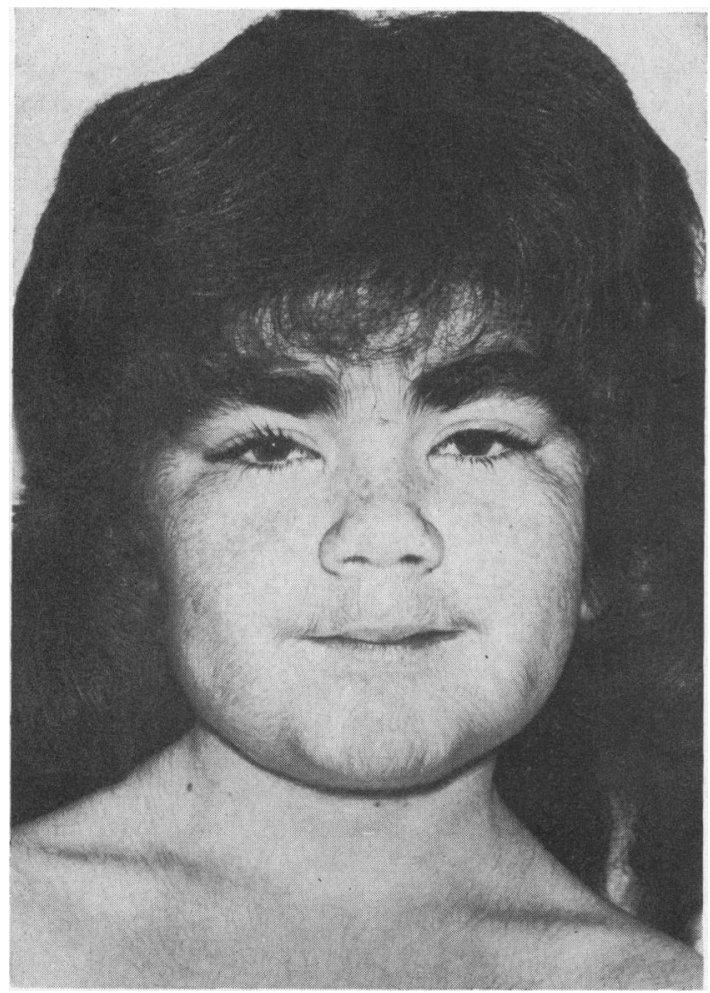

Fig. 6.-Case 2. Marked facial hypertrichosis.

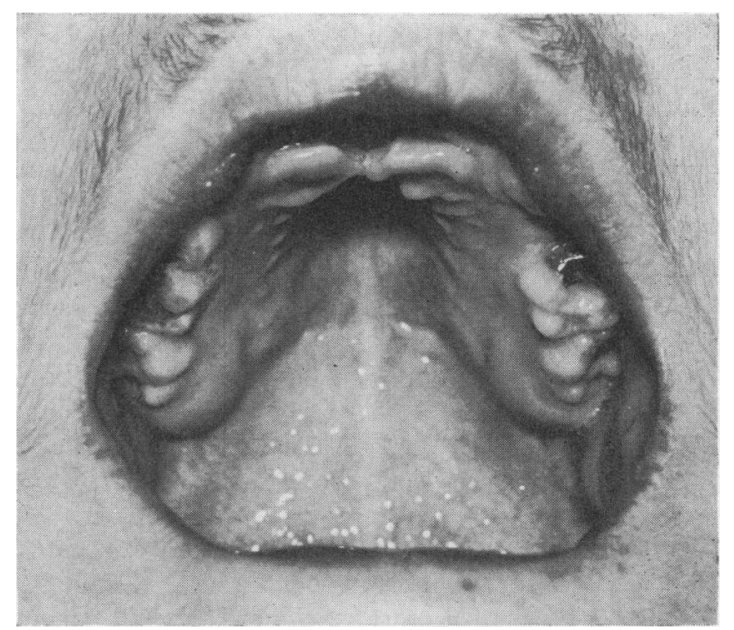

Fig. 7.-Case 2. Hyperplasia of palatal rugae.

gingivae, idiopathic hyperplasia of the gums, and diffuse fibroma of the gums. The usual mode of genetic conveyance is considered to be autosomal dominant, and sporadic cases without family history, as described above, are probably due to genetic mutation (Anderson et al., 1969). Gene frequency for the anomaly has been estimated to be $1: 350,000$ with a phenotype frequency of $1: 175,000$ (Fletcher, 1966).

Hypertrichosis noted at birth or shortly after has 
been recorded in 5 previous cases (Salter, 1870; Villa and Zarate, 1953; Snyder, 1965; Byars and Sarnat, 1945). In all other cases the excess hair developed either during childhood or at puberty. The age of onset of hypertrichosis is unrelated to the start of gingival hyperplasia (Anderson et al., 1969). While the excess hair may be fine and fair in childhood, by adult life it becomes coarse and black (Rushton, 1957); extreme disfigurement may result, with some earlier celebrated cases being described as 'hair man' (Parreidt, 1886) and 'bear woman' (Humphry, 1886). The sites of excessive hair formation are usually reported as eyebrows, face, limbs, and middle of the back. The apparent spontaneous diminution of hair on the face and back in the first case described above is therefore without precedent, if the history is correct.

Gingival hyperplasia may occasionally precede the eruption of the primary teeth and result in the delay of teething as was seen in Case 1 (Byars and Sarnat, 1945). More frequently the gingival changes are not noted until after 6 to 7 years of age when either failure or delay in the eruption of permanent teeth calls attention to the abnormality. Occasionally the gingival enlargement remains unnoticed until adult life (Rushton, 1957). The gingival changes have sometimes been limited to isolated portions of the arch; the palatal aspect of the maxillary molars and maxillary tuberosity being the most common sites (Rushton, 1957). The changes in the palatal mucosa seen in Case 2 described above are possibly a forme fruste for this more localized variety of mucosal abnormality. In this respect she appears to differ from all the previously described cases associated with hypertrichosis who were reported to have shown gingival changes. The gingival tissues are usually described as being of normal colour, firm, and finely stippled in childhood, while later the gums may acquire papillary projections. The grossly enlarged labial gingivae may prevent the closure of the lips (Perkoff, 1929) and bilateral enlargement of the palatal mucosa may meet in the midline. Though excessive bone formation in the jaws was described by Salter (1870), this has usually been restricted to apparent thickening of the alveolar processes (Rushton, 1957). None of the earlier cases appear to have shown the marked palatal tori which were a feature of Case 1. Witkop (1971) suggested that cases with bone involvement in which a tooth eruption defect is secondary to a bone defect may represent a recessive form of the disease.

While earlier writers described increase in the size of the teeth in affected cases, with excessively large incisors being noted by Salter (1870), Parreidt (1886), and Tomes and Tomes (1887), this feature has been forgotten in recent reviews of the condition. Macrodontia affecting lower second premolars as seen in Case 1 has not been recorded before.

Coarse facies, in particular with abnormalities of the nose and enlargement of the ears, has been a feature of many described cases. Other conditions noted in cases of hereditary gingival hyperplasia but which were not present in either of the children described above are mental retardation, epilepsy, and small stature. To these, Anderson et al. (1969) added the extra features of a doughy and hyperelastic skin, gross seborrhoea, multiple benign cellular naevi, and an anomaly of the second cervical vertebra. Cherubism has also been reported in association with the condition (Ramon, Berman, and Bubis, 1967). Hypertrichosis, gingival hyperplasia, and virginal hypertrophy of the breasts (giant fibroadenoma) are together seen in the distinct Cowden syndrome (Witkop, 1971). However, it may be difficult to distinguish this latter syndrome during childhood as the abnormal breast development may be delayed until early adult life. Apart from hypertrichosis, mental retardation is the only other abnormality associated with the gingival hyperplasia which has occurred often enough to warrant its inclusion in this syndrome.

Treatment with phenytoin (Epanutin) can cause hypertrichosis and gingival hyperplasia. Furthermore, pregnant women who are taking phenytoin may give birth to a baby with hypertrichosis. It is therefore of the greatest importance to confirm that this drug is not the cause of the problem. Hirsutism due to adrenal hyperplasia or tumour is easily differentiated, for the distribution of coarse hair seen in these conditions is of the male sexual pattern. Congenital hypertrichosis lanuginosa also has to be excluded. This abnormality was first described by Thomas Bartholin in 1654. It is, however, unassociated with gingival hyperplasia. Reported cases have been classified in two groups, both of which may be excessively hairy at birth. In the dog-face form the body, with the exception of the palms and soles, is covered with long silky hair from early childhood. The eyelashes are long and the eyebrows thick. This hair may grow to the length of $10 \mathrm{~cm}$, and the hypertrichosis is permanent. Defects of the external ear and hypodontia or anodontia have been recorded. In some instances the condition is associated with mental retardation. In the monkey-face form hypertrichosis is always present at birth. Affected children usually die in infancy, but if they survive they develop a broad, flat, simian face with thick drooping lips and prognathism (Ebling and Rook, 1972). 


\section{REFERENCES}

Anderson, J., Cunliffe, W. J., Roberts, D. F., and Close, H. (1969). Hereditary gingival fibromatosis. British Medical fournal, 3, 218.

Bartholin, T. (1654). Historiarum Anatomicarum Rariorum Centoria I Historia 42, p. 42. Vlacq, Amsterdam.

Byars, L. T., and Sarnat, B. G. (1945). Congenital macrogingivae (fibromatosis gingivae) and hypertrichosis. American fournal of Orthodontics and Oral Surgery: Orthodontics, 31, 48.

Ebling, F. J. G., and Rook, A. (1972). Congenital hypertrichosis lanuginosa. In Textbook of Dermatology, 2nd ed., p. $1575 . \quad$ Ed. by A. Rook, D. S. Wilkinson, and F. J. G. Ebling. Blackwell Scientific Publications, Oxford.

Fletcher, J. P. (1966). Gingival abnormalities of genetic origin: preliminary communication with special reference to hereditary generalized gingival fibromatosis. Fournal of Dental Research, 45, 597.

Gorlin, R. J., and Pindborg, J. J. (1964). Syndromes of the Head and Neck, p. 312. McGraw-Hill, New York and London.

Humphry, G. M. (1886). Unilateral hypertrophy of the gums associated with other abnormalities chiefly hypertrophic and unilateral. Annals of Surgery, 3, 1 .

Moorees, C. F. A., Thomsen, S. Ø., Jensen, E., and Yen, P. K-J. (1957). Mesiodistal crown diameters of the deciduous and permanent teeth in individuals. Fournal of Dental Research, 36, 39.
Parreidt, J. (1886). Ueber die Bezahnung bei Menschen mit abnormer Behaarung. Deutsche Monatsschrift für Zahnheilkunde, 4, 41.

Perkoff, D. (1929). Primary generalised hypertrophy of the gums. Dental Record, 49, 411.

Ramon, Y., Berman, W., and Bubis, J. J. (1967). Gingival fibromatosis combined with cherubism. Oral Surgery, Oral Medicine and Oral Pathology, 24, 435.

Rushton, M. A. (1957). Hereditary or idiopathic hyperplasia of the gums. Dental Practitioner, 7, 136.

Salter, S. J. A. (1870). A System of Surgery, 2nd ed., p. $342 . \quad$ Ed. by T. Holmes. Longman-Green, London.

Snyder, C. H. (1965). Syndrome of gingival hyperplasia, hirsutism, and convulsions. Fournal of Pediatrics, 67, 499.

Tomes, J., and Tomes, C. S. (1887). A System of Dental Surgery, 3rd ed., p. $706 . \quad$ Churchill, London.

Villa, V. G., and Zarate, A. L. (1953). Extensive fibromatosis of the gingivae in the maxilla and in the mandible in a six-year-old boy. Oral Surgery, Oral Medicine and Oral Pathology, 6, 1228.

Witkop, C. J. (1971). Heterogeneity in Gingival Fibromatosis, Vol. 7, Part II, p. 210. Birth Defects Original Article Series. Williams and Wilkins, Baltimore.

Correspondence to Professor G. B. Winter, Institute of Dental Surgery, Eastman Dental Hospital, Gray's Inn Road, London WC1X 8LD. 